\title{
Uma abordagem paranaense sobre o consumo cultural juvenil e a convergência midiática: um relato analítico
}

\section{An approach from paraná on youthful cultural consumption and media convergence: a critical account}

\author{
Regiane Regina Ribeiro ${ }^{1}$ \\ Celsi Brönstrup Silvestrin ${ }^{2}$
}

Resumo O texto é um relato da primeira fase da pesquisa "Iovem e Consumo Midiático em tempos de Convergência" no estado do Paraná. Ao utilizar dados preliminares do estudo-piloto e da etapa exploratória da pesquisa na cidade de Curitiba, o artigo apresenta um panorama do consumo midiático pelos jovens por aspectos ligados tanto às suas características conformadoras e hábitos, como às que tratam de sua presença enquanto parte ativa das práticas culturais e comunicacionais na sociedade midiatizada. Dentre essas práticas merecem destaque a convergência midiática, os novos regimes de visualidade, a vinculação dos bens culturais e midiáticos e seu caráter simbólico na construção das identidades juvenis e as performances coletivas voltadas para a sociabilização, a identificação e o reforço dos laços sociais.

Palavras-chave: Consumo midiático; Juventude; Convergência; Paraná

\footnotetext{
Abstract The text is a description on the first phase of the research "young and media consume in an epoch of convergence", conducted in the state of Paraná. Using preliminary data of the pilot study and the research exploratory stage at the city of Curitiba, the article presents a scenery on youth media consume. The

${ }^{1}$ Universidade Federal do Paraná - UFPR, Curitiba, PR, Brasil.

E-mail: regianeribeiro5@gmail.com

${ }^{2}$ Universidade Federal do Paraná - UFPR, Curitiba, PR, Brasil.

E-mail: celsibs@gmail.com
} 
study tackles their specific characteristics and habits, treating the youth as an active actor in the communicational and cultural practices in a society characterized by the presence of media. Among those practices, deserves distinction the media convergence, the new regimes of visuality, the diffusion of cultural goods and their symbolic characteristics on the construction of youthful identities, collectives performances orientated towards socialization, mutual identification and reinforcement of the social ties.

Keywords: Media consume; Youthful; Convergence; Paraná 


\section{Introdução}

O aumento excessivo de informações e possibilidades de acesso aos conteúdos midiáticos transforma consideravelmente os hábitos de recepção dos jovens e produz distintas formas de significação e apreensão de sentido das mensagens. Com base em dados coletados no Estado do Paraná na primeira fase da pesquisa da Rede Brasil Conectado "Jovem e Consumo Midiático em tempos de Convergência” foi possível sinalizar para alguns aspectos importantes no processo de aquisição e uso das tecnologias digitais, colocando sob tensão o consumo midiático e sua lógica a partir dessas novas práticas, bem como problematizar os regimes de interação causados nesses jovens com base em uma experiência estética sui generis.

O objetivo deste artigo é apresentar os resultados parciais obtidos no Paraná no subprojeto "Uma abordagem paranaense sobre o consumo cultural juvenil e a convergência midiática" . A reflexão teórica direciona-se sob a perspectiva dos Estudos Culturais Britânicos e Latino-americanos. Parte-se da premissa de que a dimensão cultural - entendendo-se a cultura como uma entidade não monolítica ou homogênea, mas diferenciada de acordo com a formação social e o momento histórico - é fundamental para se compreender as práticas de consumo dos jovens (AGGER, 1992, p. 89).

No que diz respeito às práticas de uso e apropriação de bens e serviços, considera-se a perspectiva de Nestor García Canclini, segundo a qual o consumo cultural é compreendido como "o conjunto de processos de apropriação e usos de produtos nos quais o valor simbólico prevalece sobre os valores de uso e de troca, ou onde ao menos estes últimos se configuram subordinados à dimensão simbólica" (CANCLINI, 1993, p. 34).

Inicia-se o texto com breve descrição do projeto nacional e sua configuração no estado do Paraná; na sequência é apresentado um relato sobre as tarefas realizadas até o estágio do estudo-piloto - com destaque

3 Projeto apoiado pelo CNPQ, processo n. 406286/2012-04, chamada MCTI/CNPQ/CAPES $18 / 2012$. 
para a aplicação de questionários presenciais e análise de perfis de jovens no ambiente virtual. Com base nesses dados, apresenta-se um panorama dessas formas de consumir por aspectos ligados tanto às características conformadoras do público jovem e de seus hábitos, quanto às que tratam de sua presença enquanto parte ativa das práticas culturais e comunicacionais na sociedade midiatizada. Dentre essas práticas, algumas se destacam no estado, como, por exemplo:

- Vinculação dos bens culturais e midiáticos e o seu caráter simbólico como determinante na construção das identidades juvenis.

- Pertencimento a uma coletividade, onde duas funções estão claramente entrelaçadas: sociabilização e identificação. As performances coletivas se dão como processos de inclusão e reforço de laços sociais.

- Compartilhamento e uso de imagens (novos regimes de visualidades) cada vez mais presentes nas performances dos jovens nas plataformas digitais.

- A convergência midiática como determinante no consumo de músicas, séries e filmes reorganizando as práticas de recepção e participação.

\section{Projeto Nacional x Projeto Local}

O projeto nacional "Jovem e consumo midiático em tempos de convergência” é uma iniciativa da pesquisadora Nilda Jacks ${ }^{4}$ com a finalidade de, nacionalmente, estudar e mapear o comportamento de consumo midiático dos jovens brasileiros na era digital, em uma condição sociocultural dominada pela convergência dos meios e por receptores mais ativos e inseridos no contexto da audiência. Sua problemática envolve posse das ou acesso às tecnologias digitais por parte de jovens de diferentes estratos sociais das cinco regiões do país, buscando saber se as diferenças entre as práticas condicionadas por acessos diferenciados, em contextos socioculturais distintos, podem definir processos identitários

\footnotetext{
${ }^{4}$ Coordenadora nacional do projeto de pesquisa e professora da UFRGS.
} 
similares, no âmbito de uma cultura juvenil, tomado em termos genéricos (JACKS, 2010). A equipe do Paraná, formada no início de 2012, conta atualmente com dez integrantes de três diferentes instituições, entre eles docentes e alunos de pós-graduação e de graduação, consolidando o trabalho interinstitucional da rede.

\section{Consumo Cultural, Identidades e Convergência Midiática}

Discutir o conceito de consumo cultural na contemporaneidade e o seu potencial de influência sobre os jovens não é tarefa fácil, mesmo porque o ato de consumir não está necessariamente ligado apenas ao uso ou à troca de mercadorias, mas sim a um processo simbólico de representação social. Esse processo se concretiza em novos modelos de interagir com o mundo e com as coisas. Na prática, pode-se citar como exemplo desse novo contexto a diminuição no uso coletivo do espaço urbano e o aumento considerável do consumo de divertimento doméstico.

Para Canclini (2005, p. 58-59), "o ato de consumir envolve processos culturais mais amplos, por meio dos quais se dá sentido e ordem à vida social e se constroem as identidades. Consumir seria um investimento afetivo' e não apenas um ato monetário, os bens seriam 'acessórios rituais', dando sentido ao fluxo simbólico". Assim, "consumir é tornar mais inteligível um mundo onde o sólido se evapora”. Nessa linha de raciocínio, o autor propõe seis teorias que não devem ser pensadas isoladamente para se entender as práticas de consumo. A primeira diz respeito à "reprodução da força de trabalho e da expansão do capital", a segunda é entendida como "lugar onde as classes e os grupos competem pela apropriação do produto social", a terceira enquanto "lugar de diferenciação social e distinção simbólica entre grupos”, a quarta como "sistema de integração e comunicação", a quinta como "cenário de objetivação dos desejos" e a última como "processo ritual” (CANCLINI, 1992, p. 3-5). 
Nesse sentido, quando os jovens selecionam os bens e se apropriam deles, definem o que consideram publicamente valioso, em uma mistura de representações e significações que vão desde a apropriação do produto social e a distinção simbólica até a saciedade de desejos e rituais por meio de um sistema integrado de comunicação que não necessariamente obedece a uma lógica tradicional.

Cabe pensar que as novas práticas de consumo midiático acontecem dentro de uma dimensão complexa e significativa do cotidiano. Nelas, cultura e identidade são conceitos interligados. Assim, as transformações culturais que presenciamos nos últimos anos têm afetado diretamente as identidades. Além disso, temos presenciado o aparecimento de novas formas de identificação, agora mais distantes das concepções clássicas. Hall (2003) vai dizer que esse debate não pode ser travado se deixarmos de lado as consequências trazidas pela modernidade: de um lado, o processo de globalização e o surgimento e a difusão das novas tecnologias que têm transformado estruturalmente as relações sociais; do outro, os processos de migração (livre ou forçada) que põem em cena o debate sobre o mundo pós-colonial.

Assim, a identidade é entendida como sentimento de pertencimento de realidades e conjunto de significados compartilhados (CANCLINI, 1995; HALL, 2001; KELLNER, 2001; SILVA, 2014), sua construção acontece de acordo com o posicionamento dos sujeitos na esfera social (CASTELLS, 1999). "As identidades culturais são pontos de identificação, os pontos instáveis de identificação ou sutura, feitos no interior dos discursos da cultura e da história. Não uma essência, mas um posicionamento" (HALL, 1996, p. 70).

O que de início podemos afirmar é que o consumo midiático pelos jovens paranaenses é um território cheio de sentidos, com possíveis entendimentos comuns aos demais estados e ao mesmo tempo com sua dinâmica própria. Dessa forma, passa a ser entendido como uma vertente do consumo cultural, um tipo de processo comunicativo que estimula o consumo tanto através da oferta de bens, quanto no que se refere a tendências, comportamentos, novidades, identidades, fantasias 
e desejos. Interessa-nos saber o que os jovens consomem da mídia meios e produtos/conteúdos - a maneira com que se apropriam dela (do que consomem - como a utilizam) e o contexto em que se envolvem com ela (lugares, maneiras, rotinas etc.), nunca perdendo de vista que “as práticas culturais são essencialmente humanas, desesperadamente necessárias e exigidas na turbulência das múltiplas e simbolicamente ocupáveis eras da comunicação" (GONZÁLEZ, 2012, p. 167).

Visto que uma das principais características do consumo midiático está na convergência das mídias, torna-se importante discutir esse conceito adotando a perspectiva de Jenkins. O autor define esse fenômeno como o:

[...] fluxo de conteúdos através de múltiplas plataformas de mídia, a cooperação de múltiplos mercados midiáticos e o comportamento migratório dos públicos dos meios de comunicação que vão a quase qualquer parte em busca das experiências de entretenimento que desejam (JENKINS, 2009, p. 29).

Nesse contexto, o autor redefine os meios de comunicação a partir das transformações tecnológicas, mercadológicas e, principalmente, culturais, analisando que o fluxo de conteúdos, além de perpassar múltiplos suportes e mercados, apresenta uma relação muito forte com o comportamento migratório da audiência que, como sinalizam os dados iniciais da pesquisa, oscila entre diversos canais de busca e novas experiências de entretenimento.

O argumento central na tese de Jenkins (2009) está relacionado a uma tríade de conceitos fundamentais: convergência midiática, inteligência coletiva e cultura participativa. Todos esses conceitos dialogam com o olhar da Rede Brasil Conectado, e com os dados parciais da pesquisa no Paraná, uma vez que a inteligência coletiva diz respeito a uma nova forma de consumo e a uma nova fonte de poder, e a cultura participativa caracteriza o caráter cada vez menos passivo do consumidor contemporâneo.

Assim, o consumo midiático - enquanto processo cultural - predispõe algumas características particulares evidenciadas no estudo-piloto 
que corroboram com a perspectiva dessa discussão, principalmente no que diz respeito ao conceito de narrativa transmidiática. Para o autor, a transmídia se refere a determinados modos de configuração da produção, circulação e consumo de produtos midiáticos, geralmente atrelados à indústria do entretenimento e que se caracterizam pela fragmentação do conteúdo em diversos meios de comunicação. Isso aparece de forma bastante clara nas práticas de consumo de músicas, séries e filmes em múltiplas plataformas.

Dito de outro modo, pensar na relação da convergência e das narrativas transmidiáticas pressupõe compreender que tais questões (atreladas ao consumo midiático e cultural) criam ecossistemas comunicativos (MARTÍN-BARBERO, 2002, 2009) nos quais são configuradas as forças e as relações entre sociedade, comunicação, tecnologia, cultura e economia (e tudo isso de modo simbiótico, sem a possibilidade de pensar nestas inter-relações de modo isolado do contexto de produção, divulgação e recepção das mensagens midiáticas).

Uma leitura específica do campo televisivo (pela ficção seriada) e sua relação com as estratégias transmidiáticas abordadas por Jenkins (2009) é empreendida por Lopes e Gómez (2014). Tal pensamento nos ajuda a compreender que "o planejamento e a produção transmídia não se referem apenas às mudanças de caráter tecnológico”, pelo contrário: as estratégias e as práticas transmídias alteram as lógicas do mercado no que diz respeito à produção e ao relacionamento entre tecnologias, gêneros, formatos e, até mesmo, audiências (LOPES e GÓMEZ, 2014, p. 73).

Desse modo, não apenas é levado em consideração o meio, mas a produção de conteúdos/narrativas que possam se desdobrar em diversas plataformas e que, consequentemente, modificam as formas pelos quais os jovens se relacionam com o mundo por meio do consumo.

\section{A experiência do estudo-piloto}

É importante frisar que a realização do estudo-piloto foi precedida por um levantamento de dados sobre o Paraná e Curitiba, como parte de 
um "sistema de informação" lidades estadual e local, além de compor um quadro com dados para embasar um texto sobre o contexto do estado e da cidade ${ }^{6}$.

Com relação ao Paraná, vale considerar algumas informações: localizado na região Sul, é composto por 399 municípios e possui uma população aproximada de 10 milhões de pessoas, dividida de forma equilibrada entre o sexo masculino $(49,13 \%)$ e o feminino $(50,87 \%)$. A população jovem representa $17,52 \%$ do total de habitantes (IBGE, 2010). Os jovens seguem o equilíbrio geral na divisão por sexo, invertendo a pequena diferença em direção à população masculina $(8,82 \%)$ e residem, em sua maioria (15,08\%), em zona urbana. Em relação à cor ou à raça, 11,94\% identificam-se como brancos, 4,83\% como pardos e $0,53 \%$ como sendo de cor ou raça preta. A população indígena possui $0,04 \%$ da população jovem, enquanto $0,18 \%$ identifica-se como amarela (IBGE, 2010).

Já, Curitiba, a capital do estado, situada no Primeiro Planalto Paranaense, localizada na região leste do Paraná, possui 26 municípios em sua região metropolitana, com 75 bairros e 1751907 habitantes. A população jovem curitibana soma 16,97\% do total de habitantes da cidade, dividida entre o sexo masculino $(8,47 \%)$ e o feminino $(8,5 \%)$, todos residentes em área urbana (IBGE, 2010).

Em 2013, teve início a fase da pesquisa de campo propriamente dita, com a realização do estudo-piloto, conforme protocolo fornecido pela coordenação nacional. O estudo foi composto por dois movimentos paralelos: entrevista com universitários identificados como pertencentes às "classes populares" (que ficou conhecida como pesquisa off-line) e observação dos perfis dos jovens no Facebook (pesquisa on-line).

Segundo o roteiro de orientação encaminhado pela coordenação nacional, as duas frentes de pesquisa servem para observar dinâmicas,

\footnotetext{
5 Segundo Galindo Cáceres, toda pesquisa deve iniciar pela criação de um "sistema de informação", que irá alimentar sua execução e terminar com um "sistema de comunicação", que irá garantir sua divulgação e uso social.

${ }_{6}^{6}$ Essa etapa inicial, bem como os instrumentos para os levantamentos de dados, seguiram as orientações previstas no projeto nacional.
} 
fluxos e circulação de temas/conteúdos estabelecidos pelos jovens on-line, além de explorar detalhes das práticas e dos rituais de jovens universitários nas plataformas digitais.

\section{Pesquisa off-line}

As recomendações para a realização dessa etapa do estudo-piloto foram de que os entrevistados deveriam ser jovens universitários, entre 18 e 24 anos, pertencentes às classes populares, com uma renda máxima de 1.800 reais. Para assegurar uma noção "sociocultural" de juventude, o questionário incorporou elementos como renda familiar, local e tipo de moradia, nível de instrução da família, profissões, em uma tentativa de identificar o estrato social do pesquisado, bem como, aspectos que determinassem o consumo cultural por meio de um levantamento junto a eles.

A tarefa do questionário presencial foi realizada em duas etapas. $\mathrm{Na}$ primeira houve a distribuição para duas turmas de graduação; na segunda o contato com a ONG Em Ação, que atua gratuitamente como curso preparatório para o vestibular nos fins de semana, atendendo a jovens com baixa renda, para completar a amostra. Somando as duas frentes, 11 jovens foram entrevistados. No entanto, para efeito de análise, apenas 10 tiveram seus dados compilados, de acordo com o protocolo do estudo-piloto.

No que diz respeito aos locais onde televisores e computadores são utilizados, houve preferência para sala e quarto; o quarto dos pais aparece como terceira opção; locais de mobilidade ou mesmo a cozinha não tiveram grande representatividade, o que configura que o consumo midiático a partir do local de uso está diretamente relacionado à renda familiar e à divisão dos aparelhos pelos membros da família.

Em relação à conectividade, o acesso à internet é realizado, em sua maioria, em banda larga, seguido pelo $3 \mathrm{G}$; a conexão via cabo é pouco representativa. $\mathrm{O}$ acesso representativo à banda larga se dá principalmente por uma boa estrutura midiática digital do estado, que conta hoje com 10 provedores na oferta. Em Curitiba o acesso à internet está 
presente em 340.770 domicílios da cidade, prestados por companhias como OI, GVT e NET. A presença de telefones celulares é percebida em 529.024. Estão presentes no município as seguintes operadoras de telefonia móvel: Brasil Telecom Celular S.A.; Claro S.A.; Tim Celular S.A., Sercomtel e Vivo S.A. (ANATEL, 2013). Vale ressaltar, ainda, que o acesso à banda larga no estado foi incentivado por projetos de inclusão digital desenvolvidos no âmbito do governo do estado do Paraná, bem como iniciativas não governamentais. Esses dados incidem no grande número de acesso às plataformas digitais via banda larga no estado e em como esse aspecto tecnológico determina o uso e as apropriações que o jovem pode ou não fazer nas plataformas digitais.

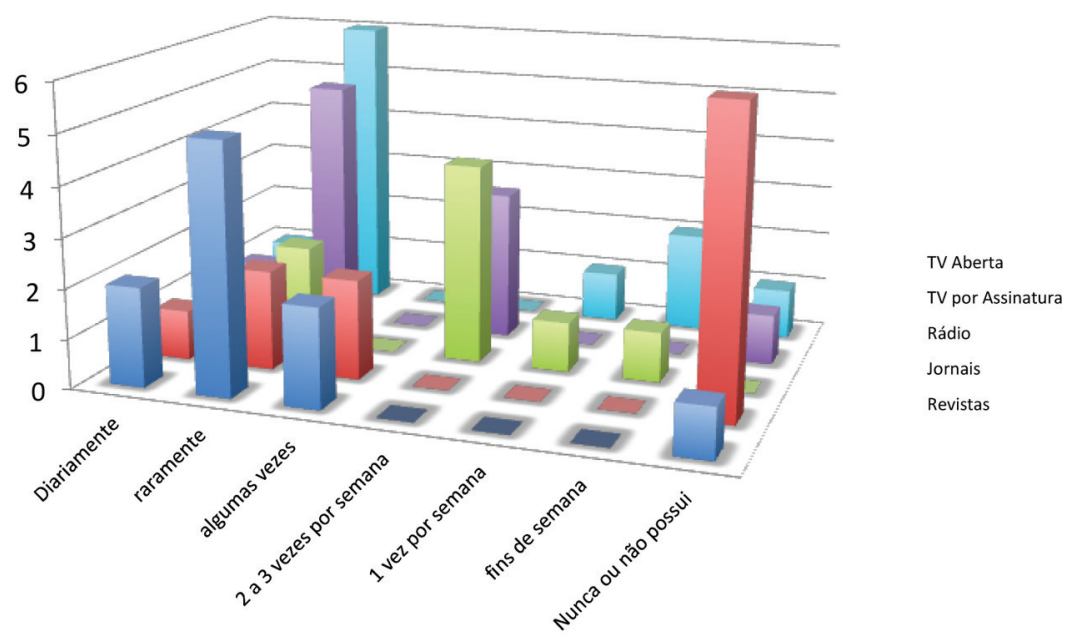

Figura 1. Usos Midiáticos.

Fonte: Dados da Pesquisa.

Os locais de acesso se dividem entre casa, faculdade/universidade e trabalho, também aparecem lan houses e centros comunitários. Em relação ao tipo de dispositivo móvel que utilizam, as respostas se dividiram igualitariamente entre celulares com acesso à internet e smartphones. No que diz respeito ao uso dos celulares, o consumo varia entre: envio 
de SMS, ouvir música, falar com amigos, acesso à internet e ligações. O acesso à internet se divide em uso de redes sociais, pesquisa e informação.

Verificou-se que a TV aberta ainda aparece como possibilidade de consumo midiático, no entanto, já se verifica um declínio no seu uso, a TV por assinatura também não é contemplada por esses adolescentes. Rádio, jornais e revistas em seus formatos originais são pouco consumidos pelos jovens paranaenses.

Quando analisados os usos de mídia pelos jovens do Paraná, o estudo piloto sinalizou para práticas que corroboram a ideia da convergência midiática e a da transmídia propostas por Jenkins (2009). O consumo de filmes e séries aparece como importante segmento para os jovens e a prática de assistir a esse gênero se dá on-line, por downloads, seguido do cinema e da TV aberta. Essa prática se dá não só na recepção e na interação com os conteúdos, como também com as novas formas de participação: comentários em redes sociais, participação em comunidades e até fenômenos como o binge-watching 7 . Outro dado relevante está na escolha da plataforma de audiência, que deixa de se concentrar na TV aberta e passa a ser realizada em outras telas, como tablets e smartphones.

Isso demonstra que o consumo midiático reflete um conjunto de ações comunicativas que transcendem um meio específico de transmissão, através da digitalização, permitindo que anseios por participação dos receptores nos processos de emissão sejam exacerbados ao ponto de gerarem esse novo conjunto de comportamentos.

Nesse contexto, como afirma Jenkins (2009), os jovens, interessados em determinados produtos, começam não só a consumir, mas a criar derivações, discutir e reunir-se para celebrar esses produtos, valorizando sua posição enquanto responsáveis pelo produto final/oficial e sua importância e influência em seu crescimento, sua continuidade e/ou sua própria criação, dando nova configuração às audiências.

\footnotetext{
7 Binge-watching, também chamado de binge-viewing, é a prática de ver televisão por intervalos mais longos do que o habitual, geralmente de um único programa de televisão.
} 


\section{Consumo de Filmes}

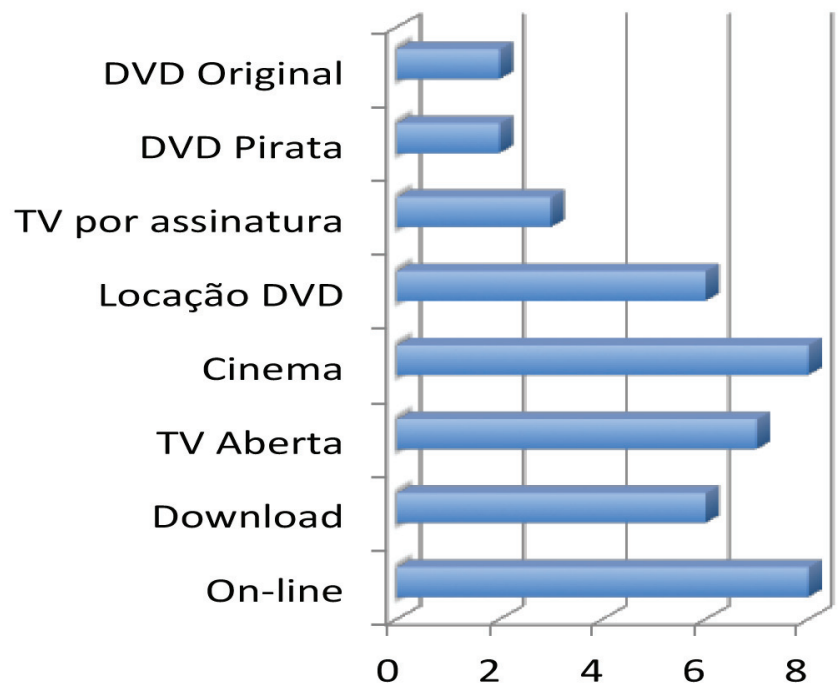

Figura 2. Consumo de filmes.

Fonte: Dados da Pesquisa.

O autor defende ainda que a ênfase na convergência não deve ser deslocada da lógica de mercado capitalista. Assim, trata-se também de estratégias concordantes com o formato globalizado de consumo que buscam dar conta dos novos padrões que o público apresenta em contato com a cibercultura (JENKINS, 2009).

No que diz respeito ao uso das redes sociais, os dados off-line convergem com os perfis analisados no Facebook (pesquisa on-line). Todos os entrevistados utilizam a rede social diariamente e em unanimidade a utilizam para se relacionar com amigos, familiares, namorados ou companheiros e colegas de trabalho. O Facebook tem destaque, a idade média de início de utilização de redes sociais digitais: 13,8 anos; a maioria iniciou pelo Orkut, também foram citados MSN e ICQ. Outras redes citadas foram Pinterest, Badoo, Google+, Tumblr, Instagram, Linkedin e Twitter. 
O consumo de serviços digitais (sites, e-mail, bate-papo etc.) tem como característica a busca por informações e contato com amigos e familiares. O principal motivo citado para participação nas redes foi a popularidade. Também apareceram nas respostas: praticidade; benefícios/recursos da rede que suprem as necessidades; costume; contato com família e colegas, interesses e notícias. Apenas duas pessoas nunca deixaram de usar alguma rede. A maioria já deixou, principalmente pelo desuso coletivo, por extinção da rede, nova interface pior, uso por poucas pessoas e acesso a outras fontes. Os períodos do dia em que ficam mais conectados são tarde e noite.

No que diz respeito à rede de usuários, a maioria dos contatos concentra-se em Curitiba e no próprio estado, os principais temas de conversas são cotidiano, estudos, interesses comuns, lazer, relacionamentos e negócios. Todos afirmaram que costumam se encontrar com seus contatos fora das redes virtuais. Quatro jovens ressaltaram que encontram quem faz parte do dia a dia, um os encontra em ocasiões específicas e outro disse que se encontra com uma parte.

Os fluxos de conteúdo abordam assuntos como: área profissional, música, fotos, curiosidades e polêmicas, livros, promoções, reflexões, humor, assuntos relacionados a cidadania, notícias, vídeos e textos e cotidiano. Três entrevistados não costumam postar, a maioria afirma ler postagens de outras pessoas; apenas três jovens disseram não reencaminhar posts. A maioria diz compartilhar conteúdos, em especial se forem de utilidade pública, humorísticos ou relacionados a posts próprios.

Verifica-se, assim, que os dados parciais do estudo-piloto off-line reforçam a ideia de que é através das redes sociais que o jovem contemporâneo toma conhecimento do mundo em que vive e tensiona sua identidade. São esses meios que o ajudam na construção da realidade, que é, portanto, formada por elementos e informações oferecidos e disparados pelo processo de midiatização hoje existente. Tais práticas aparecem com maior ênfase e serão mais aprofundadas nos dados coletados na pesquisa on-line descritos a seguir. 


\section{Pesquisa on-line}

A coleta de dados do Facebook seguiu o protocolo oficial da pesquisa nacional e analisou 11 perfis de jovens, sendo seis homens e cinco mulheres. Dos perfis analisados apenas um perfil não possui informações sobre família, todos possuem informações sobre trabalho e educação e data de nascimento, quase todos informam cidade atual, histórico, gênero, idiomas e algum link para contato (e-mail ou blog). Esse dado sinaliza que as práticas de apropriação das plataformas digitais pelos jovens estão prioritariamente relacionadas ao processo de gerar identificação com o outro, resultando em uma interação comunicativa de identificação e sociabilidade. Thompson afirma a esse respeito que:

separar a interação social do local físico, o desenvolvimento dos meios técnicos afeta, também, as maneiras como, e o quanto, os indivíduos são capazes de gerenciar sua autoapresentação. Toda ação ou desempenho se dá dentro de um referencial interativo específico que implica toda uma espécie de pressupostos, convenções e pontos de referência. Um indivíduo, agindo dentro desse referencial, adaptará a ele, até certo ponto, seu comportamento, projetando uma autoimagem que é mais ou menos compatível com o referencial (THOMPSON, 1995, p. 302).

Ou seja, os jovens cada vez mais constroem uma identidade, coerente segundo eles próprios, em um processo simbólico, por meio da utilização de materiais disponíveis na rede. Isso se apresenta nas atividades recentes dos perfis, como novas amizades, participação em eventos e páginas curtidas.

Outra característica observável diz respeito ao número elevado de amigos, o número mínimo foi de 300; dos 11 perfis, oito possuem mais de 800 amigos, sendo três deles com mais de 1.100. Em relação aos favoritos, o item que aparece em maior quantidade é música, seguido de filmes e esportes/atletas. E há ainda o fato de que alguns perfis possuem "seguidores", ou seja, possuem assinantes de suas atualizações (feeds), o que demonstra o estabelecimento de relações para além dos círculos familiares ou de amizade. 
No que diz respeito às postagens, apenas um dos perfis analisados não tinha nenhuma postagem no período de uma semana. Os temas são: frases com humor, imagens engraçadas e posts relacionados à área de estudo (atividades ou piadas da área), geralmente conteúdos compartilhados de páginas que seguem ou que amigos compartilham. E também clipes e mensagens diretas de amigos com nomes marcados. As postagens que apresentam mais repercussão geralmente envolvem humor (frases acompanhadas de imagem ou em fundos coloridos), assuntos pessoais e fotos com marcação de amigos. São raros os posts que não obtêm nenhum tipo de interação.

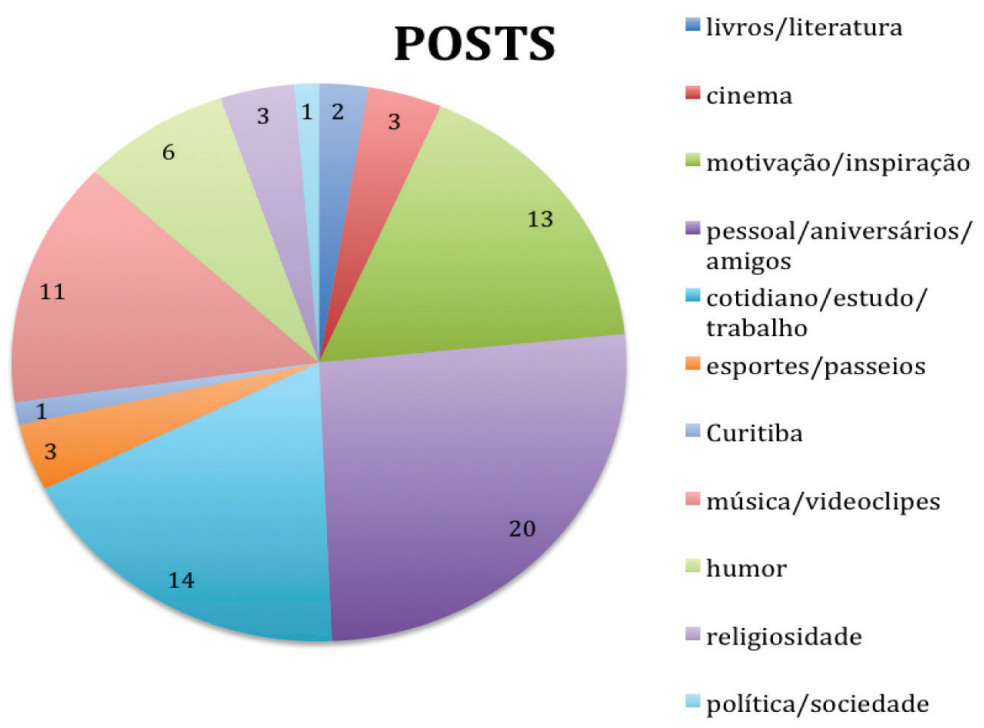

Figura 3. Categorias dos posts.

Fonte: Dados da Pesquisa.

Desta maneira, o que se observa é que quando esses jovens narram suas vidas com base em elementos do cotidiano, a identidade se apresenta não como uma essência intemporal que se manifesta, mas como uma construção imaginária que se narra. Percebe-se a emergência das redes sociais para a reorganização da identidade, assim como o cinema, o rádio e a televisão já fizeram. 
Outra evidência nas práticas de compartilhamento de imagens e conteúdos nos perfis é que os mesmos tendem a diminuir a importância dos acontecimentos fundadores e dos territórios que sustentavam a ilusão de identidades a-históricas e ensimesmadas. Esse comportamento foi evidenciado por Canclini quando afirma que

os referentes de identidade se formam agora, mais do que nas artes, na literatura e no folclore - que durante séculos produziram signos de distinção das nações -, em relação com os repertórios textuais e iconográficos gerados pelos meios eletrônicos de comunicação e com a globalização da vida urbana (CANCLINI, 1995, p. 124).

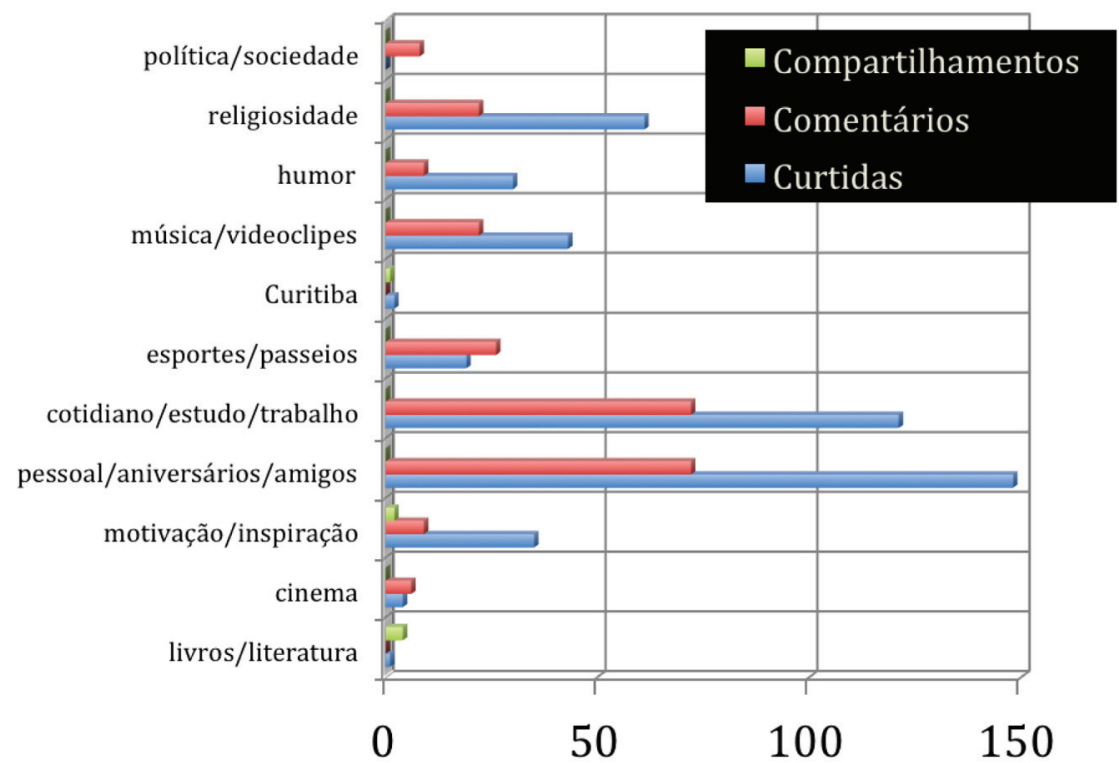

Figura 4. Dados de compartilhamentos, comentários e curtidas por assunto. Fonte: Dados da Pesquisa.

Nos perfis observados no Facebook, esses repertórios iconográficos estão cada vez mais presentes e estabelecem novos regimes de visualidade para compreensão da cultura midiática contemporânea, o crescente uso do Instagram na preferência dos jovens é um reflexo dessa prática. 
Importante destacar que, dos oito apps identificados nos perfis, quatro são exclusivos para o compartilhamento de imagens (Instagram, Pinterest, Flickr e Piccollage).

Com isso, podemos ensaiar uma conclusão prévia com base nos dados coletados no Paraná no estudo-piloto, que convergem para o ponto de vista abordado por Canclini no que diz respeito a dois desfechos para o consumo cultural na contemporaneidade: o autor propõe que a cultura, bem como a arte e a comunicação, refazem suas práticas a partir da globalização e das transformações urbanas, como também o papel da mídia na sociedade moderna (CANCLINI, 1995; 2001; 2006); e, considera a identidade e a cidadania processos fortemente atrelados na América Latina. Fica evidente, contudo, que esses dados não podem ser generalizados, pois compreendem uma amostra relativamente pequena, embora adequada para um estudo-piloto, mas se constituem importantes indícios a serem melhor explorados nas próximas etapas do projeto e confrontados com as demais regiões do país, objetivo da pesquisa nacional.

\section{Do relato à reflexão: breves considerações}

O projeto "Jovem e Consumo Midiático em Tempos de Convergência" é uma oportunidade de, na prática, pensar sobre a organização de uma pesquisa de grande porte e seus desafios. Apesar de haver um protocolo padrão, que norteia todas as equipes e busca uma homogeneidade das informações coletadas e apresentadas, existe uma diversidade cultural implicada na rede de pesquisadores, entre as regiões e entre os próprios integrantes de uma mesma equipe.

No que se refere aos primeiros resultados da experiência-piloto, a pluralidade de opções de respostas nos instrumentos de coleta de dados, de certa maneira, já demonstra uma das características desse jovem que buscamos conhecer melhor. Se, por um lado, esse conjunto amplo dificulta a pesquisa - em termos de previsão de respostas, tabulação e análise de resultados -, por outro, dá mais espaço para as múltiplas respostas possíveis, considerando o caráter transitório da juventude. 
A fase inicial, que compreendeu a produção de uma monografia com dados do estado e da capital, foi de extrema importância para a contextualização dos dados do estudo-piloto e também para as próximas fases do processo, esses dados foram organizados e publicados em livro. A delimitação da estrutura midiática de cada região e os aspectos que determinam o acesso às plataformas digitais pelos jovens, demonstraram que no Paraná esse acesso é facilitado não somente pelo número de provedores de banda larga e 3G/4G disponíveis, mas também por projetos governamentais e não governamentais de inclusão digital.

Os dados do estudo-piloto no Paraná propiciaram o reconhecimento das características da juventude e possibilitaram a ampliação do cenário a ser explorado, além de ajustar a própria formulação das questões e o estabelecimento de categorias para organização dos dados levantados para próxima fase da pesquisa. Dessas práticas, algumas se destacaram, como a vinculação dos bens culturais e midiáticos e o caráter simbólico associado a marcas e produtos, como determinantes na construção das identidades juvenis verificadas nas performances dos jovens nas redes sociais, suas narrativas, escolhas e ausências.

Nessas narrativas da própria vida e do cotidiano se estabelecem novos regimes de visualidade propiciados pelo uso cada vez maior de aplicativos ligados à produção e ao compartilhamento de imagens, principalmente o Instagram. Percebe-se que enquanto na participação do Facebook o jovem responde à questão "O que você está pensando agora?", no Instagram a pergunta é: "O que você está fazendo (vendo) agora?”, lembrando que os conteúdos do Instagram, na maioria das vezes, também são compartilhados no Facebook.

O caráter transmidiático e convergente das mídias é outro dado relevante que deve ser melhor explorado. O consumo de filmes, séries e músicas em múltiplas plataformas e a transposição da audiência em coprodutora de conteúdos, bem como a simultaneidade no uso de dispositivos no ato do consumo, são aspectos determinantes no perfil desses jovens. A análise das postagens realizadas no site de rede social, etapa em desenvolvimento, ampliará o debate qualitativamente, compreendendo 
mais detalhadamente tais práticas, rituais e fluxos que configuram suas formas de apropriação.

Por fim, a experiência de trabalhar em rede e o caráter colaborativo na busca e na troca de informações têm demonstrado, mesmo com todas as dificuldades que um projeto dessa magnitude apresenta, um importante modelo de acesso e produção de conhecimento científico. Evidentemente que somado às exigências metodológicas adotadas para assegurar a confiabilidade dos dados obtidos nas diversas etapas do estudo, o comprometimento e a conduta assumidos pelos pesquisadores são fundamentais.

Assim, entre a tensão e a satisfação de cumprir cada etapa da pesquisa dentro dos prazos estabelecidos, permanece a convicção de que se trata de uma contribuição relevante para se conhecer e se compreender um pouco mais a realidade do estado do Paraná e dos demais estados do Brasil.

\section{Referências}

AGGER, B. Cultural Studies as Critical Theory. London: The Falmer Press., 1992.

ANATEL. Relatório Anual 2012. Brasília: Anatel, 2013.

CASTELLS, M. A sociedade em rede. A era da informação: economia, sociedade e cultura. São Paulo: Paz e Terra, 1999. v. 1.

CANCLINI, N. G. Consumidores y ciudadanos: conflictos multiculturales de la globalización. México: Grijalbo, 1995.

CANCLINI, N. G. Consumidores e cidadãos: conflitos multiculturais da globalização. 5. ed. Rio de Janeiro: UFRJ, 2005.

CANCLINI, N. G. El consumo cultural en México. México: Grijalbo, 1993.

CANCLINI, N. G. Estratégias para entrar e sair da modernidade. São Paulo: EDUSP, 2006.

CANCLINI, N. G. Los estudios sobre comunicación y consumo: el trabajo interdisciplinário en tiempos neoconservadores. Dialogos de la Comunicación, n. 32, 1992. 
GONZÁLEZ, J. A. Entre cultura(s) e cibercultur@(s): incursões e outras rotas não lineares. São Bernardo do Campo: UMESP, 2012.

HALL, S. A identidade cultural na pós-modernidade. Rio de Janeiro: DP\&A, 2001.

HALL, S. Identidade cultural e diáspora. Revista do Patrimônio Histórico e Artístico Nacional. Rio de Janeiro, IPHAN, 1996.

HALL, S. Da diáspora: identidades e mediações culturais. Org. Liv Sovik. Belo Horizonte, MG: UFMG, 2003.

INSTITUTO BRASILEIRO DE GEOGRAFIA E ESTATÍSTICA - IBGE. Sinopse do Senso Demográfico de 2010. Rio de Janeiro, 2011.

JACKS, N. Jovem e consumo cultural em tempos de convergência. Porto Alegre, 2010. Rede Brasil Conectado. Disponível em: http://redebrasilconectado.wordpress.com/projeto/. Acesso em: 22 jul. 2014.

JENKINS, H. Cultura da convergência. São Paulo: Aleph, 2009.

KELLNER, D. A cultura da mídia: estudos culturais, identidade e política entre o moderno e o pós-moderno. Bauru: EDUSC, 2001.

LOPES, M. I. V.; GÓMEZ, G. O. Estratégias de produção transmídia na ficção televisiva. Porto Alegre: Sulinas, 2014.

LOPES, M. I. V.; GÓMEZ, G. O. Síntese comparativa dos países Obitel em 2013. In: MARTÍN-BARBERO, J. Dos meios às mediações: comunicação, cultura e hegemonia. Trad. Ronald Polito; Sérgio Alcides. Rio de Janeiro: Editora UFRJ, 2009.

MARTÍN-BARBERO, J. Oficio de cartógrafo: travesías latinoamericanas de la comunicación en la cultura. Santiago, Chile: Fondo de Cultura Económica, 2002.

SILVA, T. T. (Org.). Identidade e diferença: a perspectiva dos estudos culturais. 14. ed. Petrópolis/RJ: Vozes, 2014.

THOMPSON, J. B. Ideologia e cultura moderna: teoria social crítica na era dos meios de comunicação de massa. 4. ed. Petrópolis, RJ: Vozes, 1995. 


\section{Sobre os autores}

Regiane Regina Ribeiro - Professora adjunta da Universidade Federal do Paraná e docente permanente do Mestrado em Comunicação na linha de pesquisa Comunicação, Educação e Formações socioculturais. Atualmente, coordena a pesquisa Representação da Mulher Latina no audiovisual: estereótipos, limitações e ressignificações e é coordenadora do projeto Jovem e Consumo Cultural em Tempos de Convergência: um olhar sobre o Estado do Paraná.

Celsi Brönstrup Silvestrin - Pesquisadora do grupo de pesquisa Comunicação Pública \& Comunicação Política (CNPq) - PPGCOM/USP e colaboradora no Projeto de Pesquisa (nacional): Jovem e Consumo Midiático em Tempos de Convergência (PPGCOM/UFRGS), integrando a Equipe Paraná.

ORCID: htt//:orcid.org/0000-0003-1110-2902

Data de submissão: 16/09/2015

Data de aceite: 25/05/2016 